\title{
The Thermal Properties of Polyurethane/Neoprene Blends on Prosthetic Foot
}

\author{
Mohd Zulkifli Mohamad Noor ${ }^{\text {1, a*, }}$ Mohamad Anas Mohd Azmi ${ }^{1, b,}$ Mohd Shaiful Zaidi Mad Desa ${ }^{1, c,}$ \\ Mohd Bijarimi Mat Piah ${ }^{1, d,}$ Azizan Ramli ${ }^{1, e}$ \\ 1Faculty of Chemical \& Natural Resources Engineering, \\ Universiti Malaysia Pahang, 26300 Gambang, Pahang, Malaysia. \\ a*mzulkifli@ump.edu.my,b anas_mohdanas@yahoo.com , c shaiful@ump.edu.my, \\ d bijarimi@ump.edu.my, e azizanramli@ump.edu.my
}

\begin{abstract}
:
Neoprene reinforced polymer has become an attraction in current research and development of new material blend. In this invention, neoprene was chosen to be enhance to polyurethane because of their superior properties that possess extraordinary mechanical, electrical, optical and thermal properties on prosthetic foot. In this research, polyurethane was chosen due to good rigidity, easy processing and low cost. The reinforcement polyurethane with neoprene is expected to improve the properties of polyurethane. The objective of this research was conducted to investigate the effect of neoprene contents on thermal properties of polyurethane reinforced neoprene on prosthetic foot. The effect of neoprene on thermal properties neoprene reinforced polyurethane was analysed in term of its thermal stability by thermal gravimetric analysis (TGA). Moreover, the visual of small topographic details on the surface of polyurethane/neoprene blends will be examined by scanning electron microscope (SEM). Based on result, the thermal properties show the great enhancement at high neoprene contents which is $1.0 \mathrm{wt} \%$. The thermal stability of polyurethane reinforced neoprene improves when the temperature where decomposition starts to occurs are higher than decomposition temperature of pure polyurethane. Then, thermal conductivity of polyurethane shows the great improvement after the addition of neoprene. Lastly, the smooth surface and visible of sheets pattern on surface represent the present of neoprene disperse into polymer that enhance brittleness. Thus, the presence of neoprene has clearly enhanced the thermal stability of the polyurethane. Table 1 shows formulation of neoprene and polyurethane.
\end{abstract}

Keywords : Polyurethane; Neoprene; Prosthetic Foot; TGA; Thermal Stability 


\section{Acknowledgment}

Thanks to Faculty of Chemical and Natural Resources Engineering Universiti Malaysia Pahang and Research \& Innovation center for giving the research grant RDU180325 to run out the research study under internal research project scheme with the Centre of Excellence for Advanced Research in Fluid Flow (CARIFF). 